Case Report

\title{
Primary Angiosarcoma of Urinary Bladder: 13th Reported Patient
}

\author{
Zaher Bahouth, ${ }^{1,2}$ Ismael Masarwa, ${ }^{1,2}$ Sarel Halachmi, ${ }^{1,2}$ and Ofer Nativ ${ }^{1,2}$ \\ ${ }^{1}$ Bnai-Zion Medical Center, 3339313 Haifa, Israel \\ ${ }^{2}$ Faculty of Medicine, Technion Institute of Technology, 3200003 Haifa, Israel
}

Correspondence should be addressed to Zaher Bahouth; zaher.bahouth@b-zion.org.il

Received 30 July 2014; Accepted 9 January 2015

Academic Editor: Paul D. Terry

Copyright (C) 2015 Zaher Bahouth et al. This is an open access article distributed under the Creative Commons Attribution License, which permits unrestricted use, distribution, and reproduction in any medium, provided the original work is properly cited.

\begin{abstract}
Angiosarcoma of the urinary bladder is an extremely rare and poorly characterized tumor. We are presenting the 13th reported patient who was an 89-year-old man initially presented with massive hematuria. His past medical history included externalbeam radiation for prostate cancer 12 years ago. His PSA was $0.26 \mathrm{ng} / \mathrm{dL}$. His CT-Urography demonstrated a highly vascular mass originating from the bladder base. The mass was partially resected, transurethrally. The pathology was consistent with primary angiosarcoma of the urinary bladder. Bone scan and CT-U showed metastasis to spine. The patient was treated with palliative radiotherapy for back pain due to metastasis, and he refused chemotherapy. The patient died 3 months after his initial diagnosis.
\end{abstract}

\section{Introduction}

Nonurothelial tumors of the urinary bladder represent less than $5 \%$ of all bladder tumors, with sarcoma being the most common of which [1]. Angiosarcoma, one of the rarest types of sarcoma, arises from the endothelial layer of blood vessels. It is a highly aggressive cancer and carries very poor prognosis. Only 12 cases of primary angiosarcoma of the urinary bladder have been reported so far [2]

\section{Case Presentation}

2.1. The Patient. An 89-year-old male presented to ER with massive hematuria. Two large caliber intravenous cannulas were placed and blood tests for $\mathrm{CBC}$, biochemistry, and blood type were taken. A 3-way 22Fr catheter was urethrally inserted and bladder irrigation with normal saline started. His past medical history included $\mathrm{T} 1$ prostatic adenocarcinoma for which he received external beam radiotherapy 12 years ago. His physical examination and digital rectal examination were unremarkable. His creatinine was $0.9 \mathrm{mg} / \mathrm{dL}$, PSA was $0.26 \mathrm{ng} / \mathrm{mL}$, and cytology was negative for malignant cells. CT-Urography demonstrated a large highly vascular mass with irregular margins originating from the left bladder wall (Figure 1(a)). Computed tomography also showed severe left-sided hydronephrosis and hydroureter (Figure 1(b)) and lytic lesions in the vertebrae and pelvic bones suspected as metastases. Cystoscopy showed a large solid mass arising from the bladder base which was resected transurethrally.

2.2. Histopathology. Macroscopically, the specimen was $6 \times$ $5 \times 4 \mathrm{~cm}^{3}$ of grey tissue and blood clots. Microscopically, the tissue diagnosis was consistent with primary angiosarcoma of urinary bladder invading muscularis layer, with anastomosing vascular channels (Figure 2(a)). The tumor strongly stained for CD31 and CD34 and focally for fVIII (Figures 2(b) and 2(c)), three markers for endothelial cells, and was negative for Keratin P63, a marker of epithelial cells (Figure 2(d)). No prostatic tissue was found in the specimen.

2.3. Treatment. The patient was referred to palliative radiotherapy because of symptomatic spinal metastasis. The patient was consulted about the option of chemotherapy but he denied. The patient died 3 months after the initial diagnosis. 

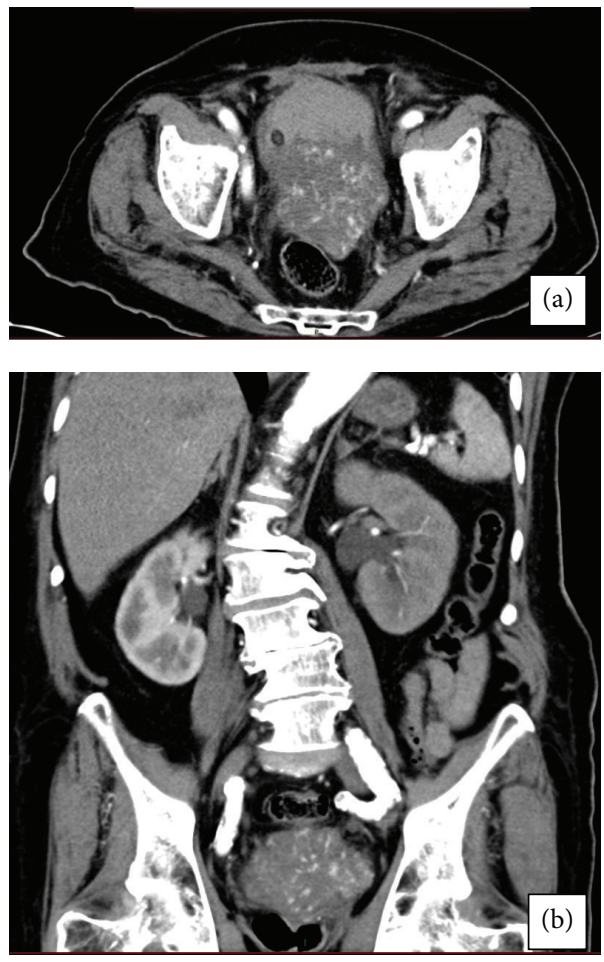

FIGURE 1: Computed tomography of our patient. (a) Highly vascular mass originating from the left bladder wall, but a prostatic origin could not be absolutely rolled out by CT. (b) Hydronephrosis on the left side and coronal view of the mass.

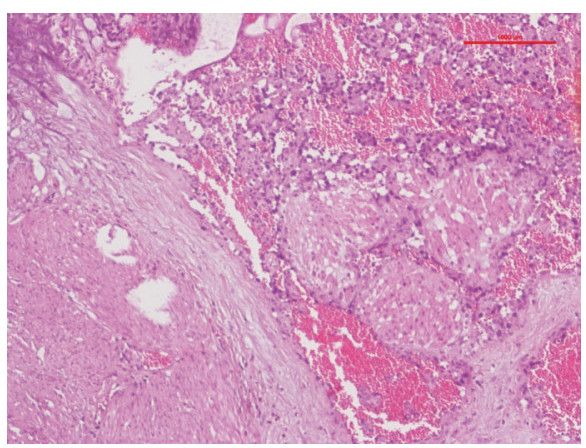

(a)

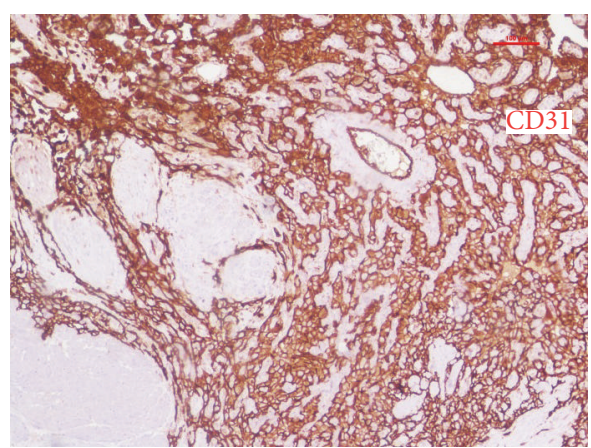

(c)

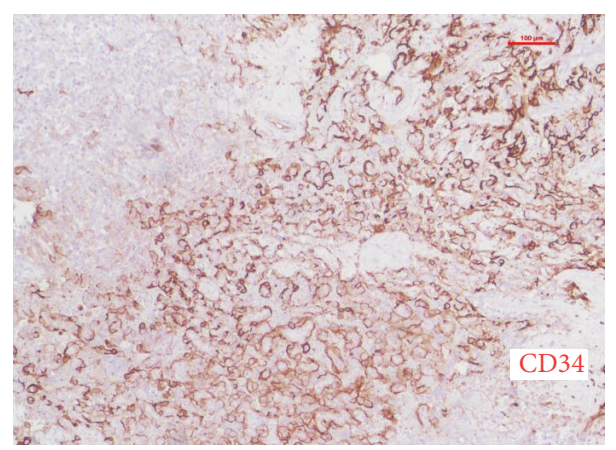

(b)

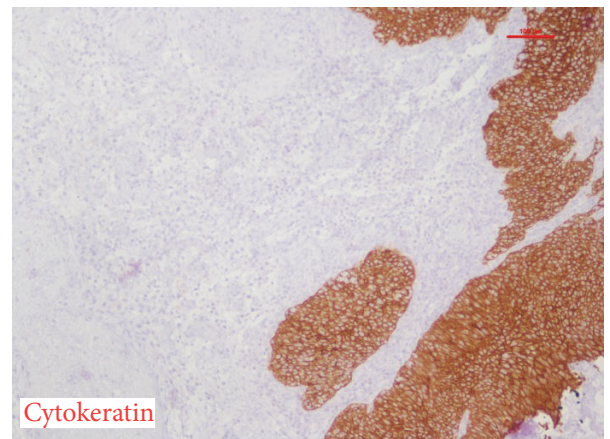

(d)

FIGURE 2: Histopathology and immunohistochemistry. (a) Typical appearance of anastomosing vascular channels as seen with H\&E. (b) Tumor cells stain positive for CD34. (c) Tumor cells stain positive for CD31. (d) Tumor cells do not stain for cytokeratin. 
TABLE 1: All reported patients' characteristics.

\begin{tabular}{lcccc}
\hline Patient & Age/sex & Etiology & Presentation & Author/year \\
\hline 1 & $54 / \mathrm{M}$ & Hemangioma & Hematuria and obstruction & Jungano, 1907 [10] \\
2 & $85 / \mathrm{F}$ & Hemangioma & Hematuria, dysuria, and weight loss & Casal et al., 1970 [11] \\
3 & 68/M & Primary & Hematuria & Stroup and Chang 1987 [12] \\
4 & $78 / \mathrm{M}$ & Primary & Hematuria, dysuria & Aragona et al., 1991 [13] \\
5 & $55 / \mathrm{M}$ & Primary & Hematuria & Ravi, 1993 [14] \\
6 & $78 / \mathrm{M}$ & RT 13 years prior to Dx & Hematuria & Navon et al., 1997 [15] \\
7 & $47 / \mathrm{M}$ & Primary & Hematuria, flank pain, and suprapubic pain & Engel et al., 1998 [7] \\
8 & $47 / \mathrm{M}$ & Primary & Dysuria and subsequent hematuria & Schindler et al., 1999 [16] \\
9 & $66 / \mathrm{M}$ & RT 4 years prior to Dx & Hematuria & Seethala et al., 2006 [8] \\
10 & $83 / \mathrm{F}$ & RT 14 years prior to Dx & Microhematuria & Kulaga et al., 2007 [17] \\
11 & $71 / \mathrm{M}$ & RT 10 years prior to Dx & Hematuria & Williams et al., 2008 [18] \\
12 & 32/F & Primary & Flank pain, hematuria & Warne et al., 2011 [2] \\
Current & $89 / \mathrm{M}$ & RT 13 years prior to Dx & Hematuria & Bahouth, 2015 \\
\hline
\end{tabular}

TABLE 2: Histopathology and immunohistochemistry of all patients reported.

\begin{tabular}{lcccc}
\hline Patient & Stage & Histology & Immunophenotype & Author/year \\
\hline 1 & N/A & Classic, focally with large dilated & Nascular spaces & Jungano, 1907 [10] \\
2 & N/A & Classic, focally solid & Casal et al., 1970 [11] \\
3 & At least lamina propria & Typical, "hobnail” cells & fVIII+, keratin- & Stroup and Chang 1987 [12] \\
4 & T3 & Typical & fVIII+, keratin- & Aragona et al., 1991 [13] \\
5 & T2 & Typical & N/A & Ravi, 1993 [14] \\
6 & T3 & Typical & fVIII+, CD34+ & Navon et al., 1997 [15] \\
7 & T4N0M0 & Solid and primitive & fVIII+, CD31+, CD34+ & Engel et al., 1998 [7] \\
8 & TXN + M0 & Solid, focally classic & fVIII-, CD34-, keratin-, CD31+ & Schindler et al., 1999 [16] \\
9 & Peritoneal surface & Solid, focally primitive & CD31+, CD43+, kertin- & Seethala et al., 2006 [8] \\
10 & Muscularis & Typical & CD31+, CD34-, fVIII- & Kulaga et al., 2007 [17] \\
11 & T4 & Typical & fVIII+, CD31+, CD34+ & Williams et al., 2008 [18] \\
12 & MIBC & Typical & fVII+, CD31+, CD34+ & Warne et al., 2011 [2] \\
Current & MIBC & Typical & CD31+, CD34+, fVIII+, keratin-; & Bahouth, 2015 \\
\hline
\end{tabular}

Typical appearance includes anastomosing vascular channels. N/A: not available. MIBC = muscle-invasive bladder cancer.

\section{Discussion}

Nonurothelial neoplasms of the urinary bladder are extremely rare. Of these neoplasms, sarcoma represents the most common nonurothelial neoplasm of the urinary bladder [1]. The most common sarcoma of the bladder is leiomyosarcoma, which accounts for more than half of the sarcomas [1]. Angiosarcoma of the urinary bladder is a very rare subtype of sarcoma with only 12 reported cases [2]. All 12 cases reported presented with hematuria, 11 with gross hematuria, and one with microscopic hematuria. Almost all cases were muscle-invasive tumors. Twelve patients' characteristics are summarized in Table 1. Histological and immunohistochemical features are summarized in Table 2.

Four cases of secondary angiosarcoma of the bladder were previously reported, originating from the penis [3], pelvis [4], Kaposi's sarcoma [5], and vagina [6].
Angiosarcoma is a very aggressive tumor carrying poor prognosis [7]. Most of the angiosarcomas are at least muscleinvasive when diagnosed [8]. Hematuria, the most common presenting symptom, may be life-threatening. Histolopathology mostly establishes the diagnosis, with typical microscopic features and immunohistochemical staining [8]. Cytology may be helpful in some cases [9].

Prior radiation is a well-documented risk factor [4] and should raise a suspicion of angiosarcoma in patients with hematuria and no evidence of urothelial carcinoma. Of the 13 angiosarcoma cases reported, including the one we are reporting, 38\% were related to prior exposure to radiotherapy.

Because of the small number of patients reported, there is no accepted gold-standard treatment. Suggested treatment options include chemotherapy, radiotherapy, and radical surgery, with some sort of combinations $[2,8]$. 


\section{Conflict of Interests}

The authors declare that there is no conflict of interests regarding the publication of this paper.

\section{References}

[1] P. Dahm and J. E. Gschwend, "Malignant non-urothelial neoplasms of the urinary bladder: a review," European Urology, vol. 44, no. 6, pp. 672-681, 2003.

[2] R. R. Warne, J. S. L. Ong, B. Snowball, and J. B. Vivian, "Primary angiosarcoma of the bladder in a young female," BMJ Case Reports, 2011.

[3] J. M. Wasmer, N. L. Block, V. A. Politano, and F. Tejada, "Penile angiosarcoma presenting in bladder," Urology, vol. 18, no. 2, pp. 179-180, 1981.

[4] D. M. Nanus, D. Kelsen, and D. G. C. Clark, "Radiation-induced angiosarcoma," Cancer, vol. 60, no. 4, pp. 777-779, 1987.

[5] R. A. Schwartz, J. F. Kardashian, N. S. McNutt, W. R. Crain, K. L. Welch, and S. H. Choy, "Cutaneous angiosarcoma resembling anaplastic Kaposi's sarcoma in a homosexual man," Cancer, vol. 51, no. 4, pp. 721-726, 1983.

[6] M. A. Morgan, D. M. Moutos, C. J. Pippitt Jr., R. R. Suda, J. J. Smith, and G. R. Thurnau, "Vaginal and bladder angiosarcoma after therapeutic irradiation," Southern Medical Journal, vol. 82, no. 11, pp. 1434-1436, 1989.

[7] J. D. Engel, T. M. Kuzel, M. C. Moceanu, M. G. Oefelein, and A. J. Schaeffer, "Angiosarcoma of the bladder: a review," Urology, vol. 52, no. 5, pp. 778-784, 1998.

[8] R. R. Seethala, J. A. Gomez, and F. Vakar-Lopez, "Primary angiosarcoma of the bladder primary angiosarcoma of the bladder," Archives of Pathology and Laboratory Medicine, vol. 130, no. 10, pp. 1543-1547, 2006.

[9] S. Lott, A. Lopez-Beltran, R. Montironi, G. T. MacLennan, and L. Cheng, "Soft tissue tumors of the urinary bladder. Part II: malignant neoplasms," Human Pathology, vol. 38, no. 7, pp. 963977, 2007.

[10] F. Jungano, "Sur un cas d'angio-sarcome de la vessie," Annales des Maladies des Organs Genitourinarie, vol. 25, pp. 1451-1461, 1907.

[11] J. Casal, E. D. Singer, and J. M. Monserrat, "Angiosarcoma of the bladder," Revista Argentina de Urología y Nefrología, vol. 39, no. 1, pp. 53-55, 1970 (Spanish).

[12] R. M. Stroup and Y. C. Chang, "Angiosarcoma of the bladder: a case report," The Journal of Urology, vol. 137, no. 5, pp. 984-985, 1987.

[13] F. Aragona, E. Ostardo, T. Prayer-Galetti, R. Piazza, and G. Capitanio, "Angiosarcoma of the bladder: a case report with regard to histologic and immunohistochemical findings," European Urology, vol. 20, no. 2, pp. 161-163, 1991.

[14] R. Ravi, "Primary angiosarcoma of the urinary bladder," Archivos Espanoles de Urologia, vol. 46, no. 4, pp. 351-353, 1993.

[15] J. D. Navon, M. Rahimzadeh, A. K. Wong et al., "Angiosarcoma of the bladder after therapeutic irradiation for prostate cancer," Cancer, vol. 60, pp. 1359-1360, 1997.

[16] S. Schindler, D. V. S. de Frias, and G. H. Yu, "Primary angiosarcoma of the bladder: cytomorphology and differential diagnosis," Cytopathology, vol. 10, no. 2, pp. 137-143, 1999.
[17] A. Kulaga, A. Yilmaz, R. P. Wilkin, and K. Trpkov, "Epithelioid angiosarcoma of the bladder after irradiation for endometrioid adenocarcinoma," Virchows Archiv, vol. 450, no. 2, pp. 245-246, 2007.

[18] S. K. Williams, R. L. Romaguera, and B. Kava, "Angiosarcoma of the bladder: case report and review of the literature," TheScientificWorldJournal, vol. 8, pp. 508-511, 2008. 


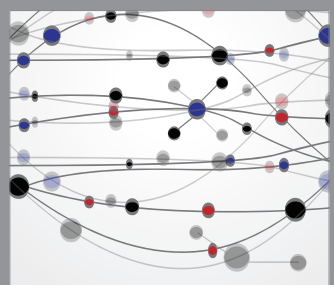

The Scientific World Journal
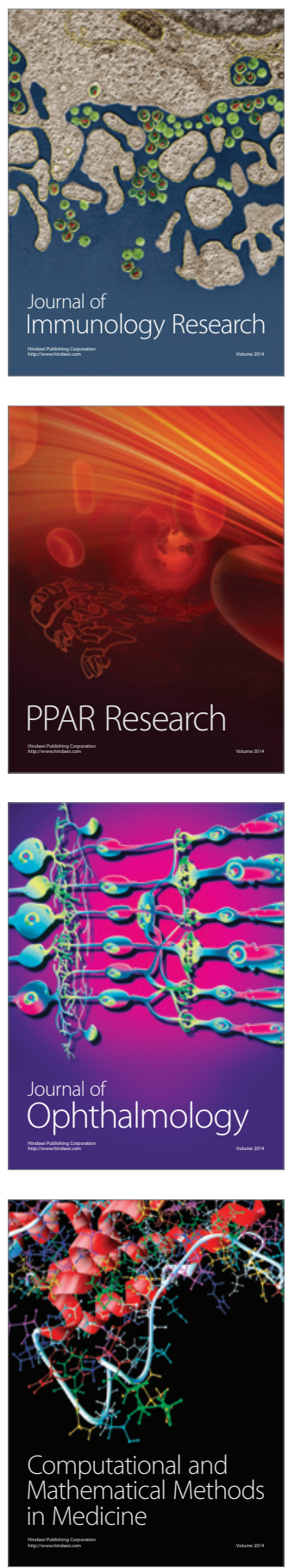

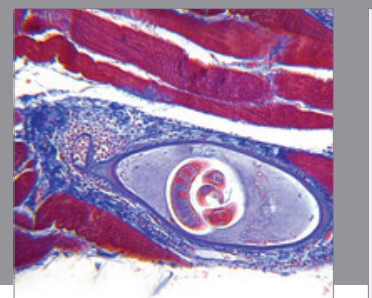

Gastroenterology

Research and Practice
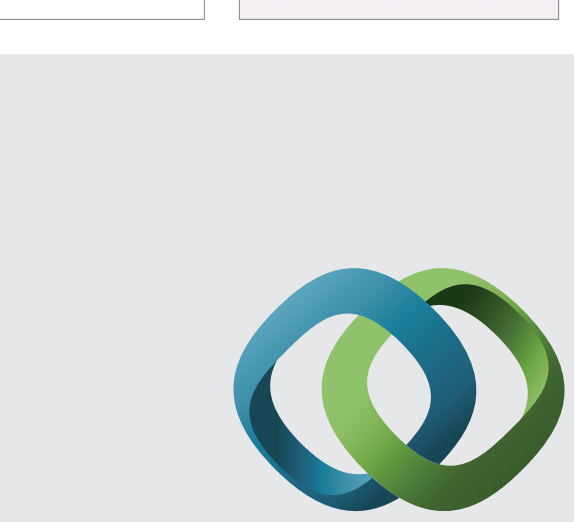

\section{Hindawi}

Submit your manuscripts at

http://www.hindawi.com
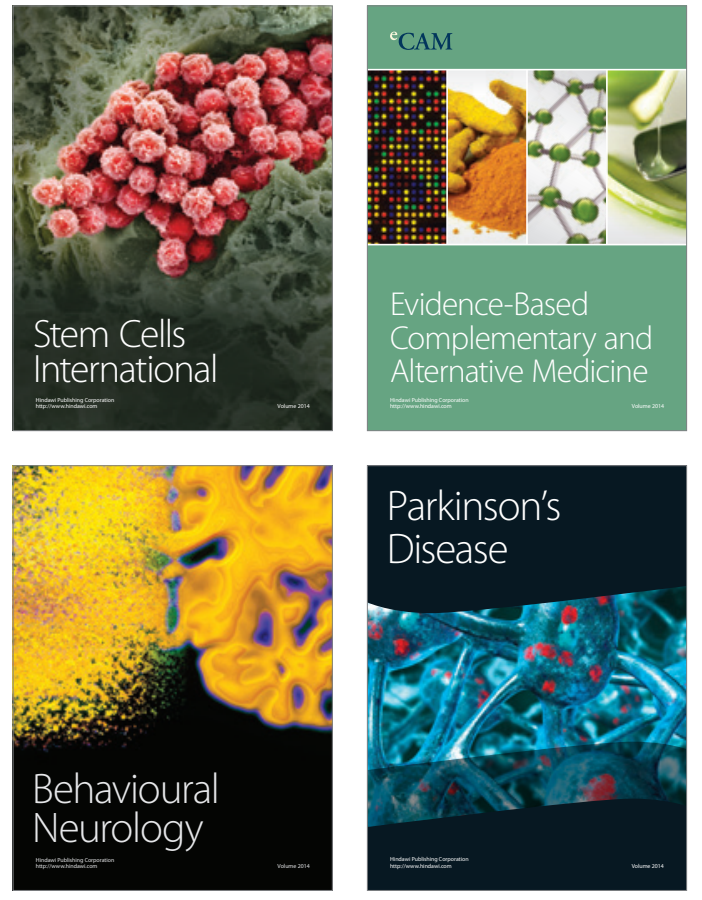
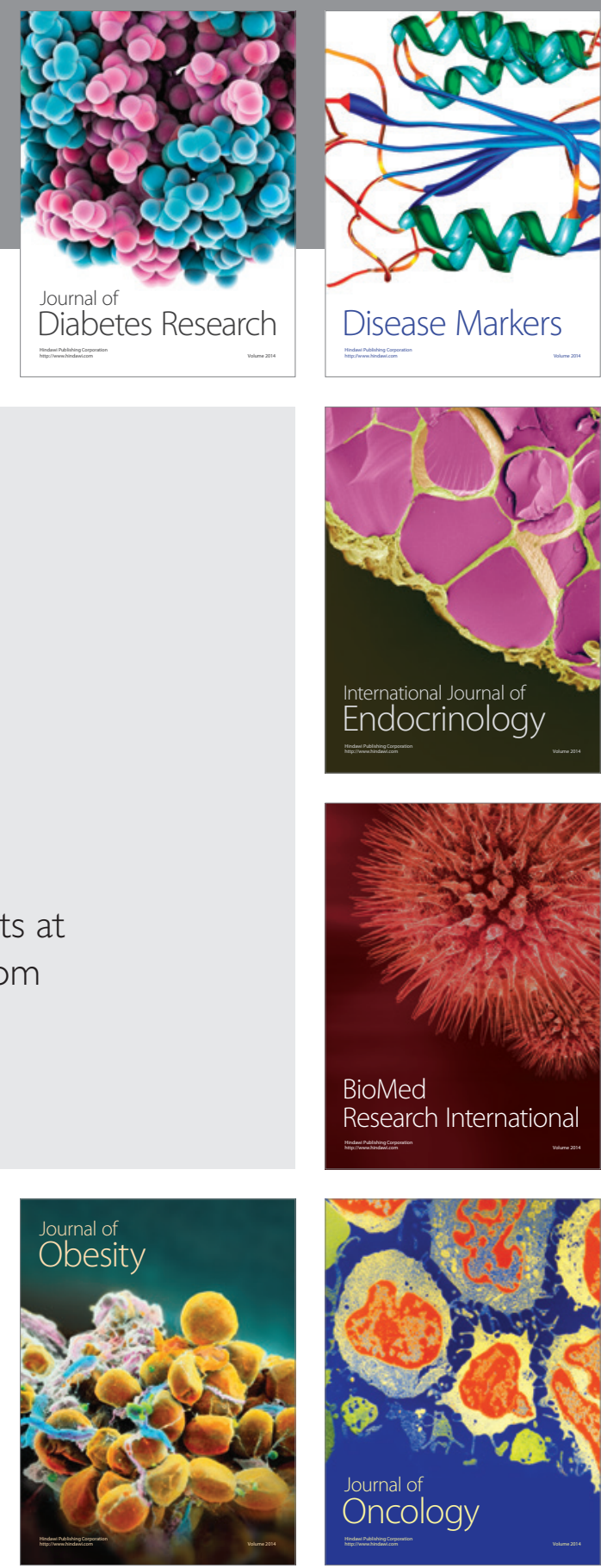

Disease Markers
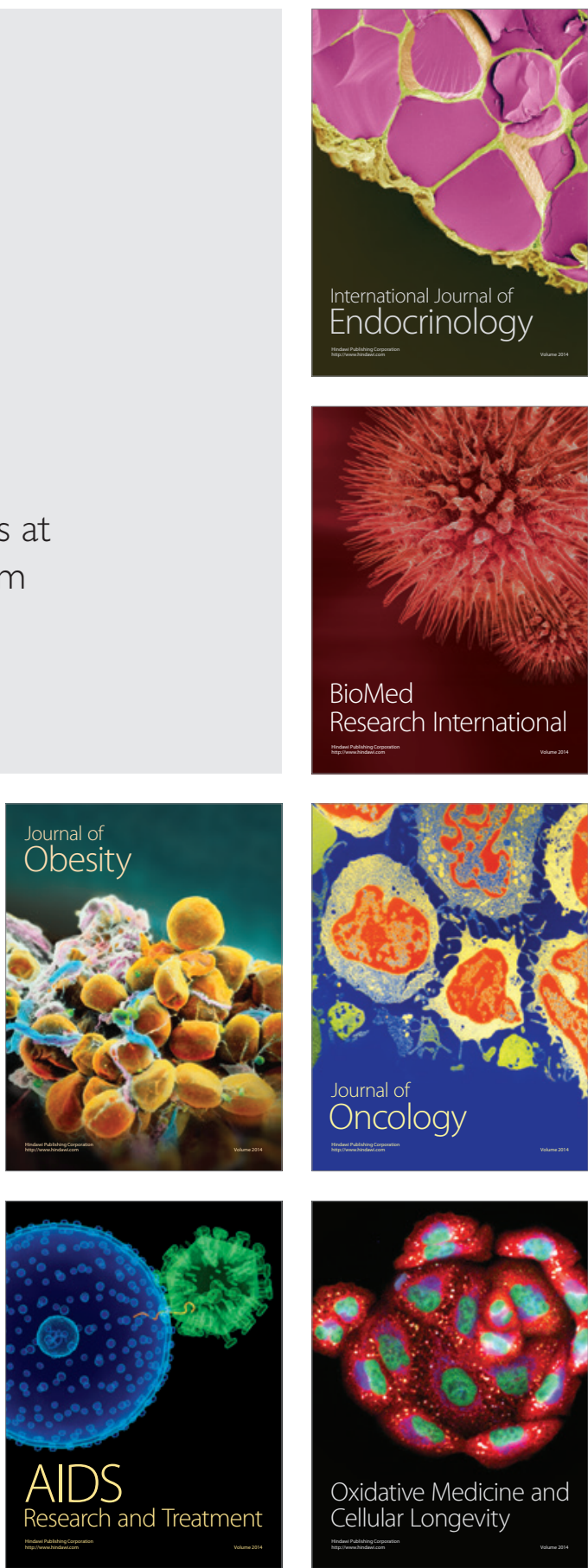